\title{
News, Announcements, and IASP
}

\section{In Memoriam: Dr. Jan Mokkenstorm (1962-2019)}

\author{
Renske Gilissen and Ad Kerkhof
}

We've lost an amazing champion in the mental health and suicide prevention fields. Jan Mokkenstorm (1962-2019), Dutch psychiatrist, CEO and founder of 113 Suicide Prevention lifeline in The Netherlands, died peacefully in his home on 8th of July 2019, after a year of illness. With his death we lost an important figurehead in the global fight against suicide.

Dr. Mokkenstorm broke the taboo on suicide early on in his career by sharing his personal story of recovering from his own suicidality. This personal experience, along with his clinical work, made him a leader in "systematizing hope, support and healing for individuals suffering from suicidal thoughts," an effort he began over 20 years ago. In 2009, Jan founded 113 Suicide Prevention. Under his direction, 113 developed into the leading suicide prevention organization in The Netherlands with a crisis helpline, research, training, and national implementation programs.

A few years ago, Dr. Mokkenstorm adopted a zero suicide approach in healthcare suicide prevention, and helped craft the International Zero Suicide Declaration (The Rotterdam Declaration) he envisioned would lead to a tipping point for the reduction of suicides. He completed his $\mathrm{PhD}$ in March of 2019 with a thesis called, "On the road to zero suicides: Implementation studies."

This dissertation provides a collection of studies of two suicide prevention strategies that aim to improve healthcare for people at risk for suicide. The first strategy aims to implement a national e-mental health platform offering online suicide prevention interventions that can be accessed anonymously, 24/7 and free of charge. The second strategy is the implementation of evidence-based suicide prevention policies and practices in specialist mental healthcare. The research presented in Dr. Mokkenstorm's dissertation focuses on the process and progress of these strategies as they were developed and implemented by 113 Suicide Prevention. As the research shows, both strategies have led to promising improvements in the quality of healthcare suicide prevention in The Netherlands. A PDF of the dissertation can be downloaded at https://www.113. $\mathrm{nl} /$ informatie/proefschrift-road-zero-suicides-implementation-studies
With this dissertation and his zero suicide approach, Dr. Mokkenstorm expressed an aspirational view of a future in which no one dies alone and in despair by suicide as a result of excellent healthcare, as well as his conviction that by acting upon this aspiration in a committed, systematic, and sustained manner, many - and perhaps most - suicides can be prevented. He never shied away from confrontations with colleagues who seemed to accept the inevitability of suicides by "untreatable" patients. He fought for every suicidal patient.

In 2014, Jan was awarded the title of Radical Innovator of the Year by Vrij Neederland. In 2016, he received the Dutch Ivonne van de Ven Award for his achievements in suicide prevention. In 2018, the Dutch Majesty King Willem-Alexander knighted him in the Order of the Dutch Lion for his work for the prevention of suicide.

His death is a great loss for the international community working in suicide prevention. He will be deeply missed by his family, friends, and all who knew him.

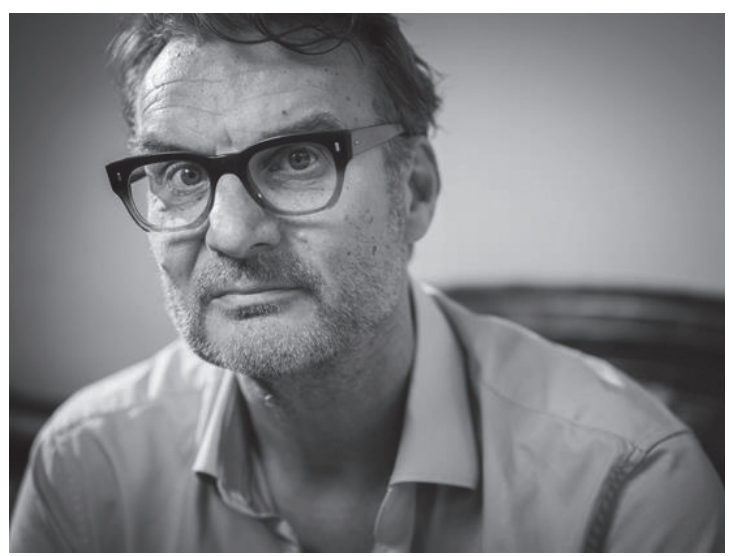

Dr. Jan Mokkenstorm. (Photo @ Merlijn Doomernik)

\section{Renske Gilissen}

113 Suicide Prevention

Amsterdam

The Netherlands

r.gilissen@113.nl 